\title{
Chiropractic assistance to firefighters from ICMBIO and IBAMA in Chapada dos Veadeiros - GO - Brazil
}

\author{
Serena Eluf de Quadros ${ }^{1}$ e Isadora Tessler ${ }^{2}$
}

${ }^{1}$ ICMBio volunteering (Serena.eluf@ gmail.com)

${ }^{2}$ Autonomous

\begin{abstract}
In 2018, I performed a Chiropractic Sessions research-through ICMBIO's volunteer program - with ICMBIO and IBAMA PREVFOGO Firefighters from Chapada dos Veadeiros National Park in the state of Goiás totalizing 111 firefighters. The goal was to use Chiropractic to improve their Quality of Life and better adapt them to develop a higher performance in action (putting down forest fires). The Chiropractor is a health technician specialized in the spinal that is dedicated on minimizing and correcting spinal subluxations(blockages in the central nervous system) to help improve the functioning of the body as a whole (immunity and performance improvements, better adaptation to any kinds of stress). A worldwide validated, quality of life questionnaire (WHOQOL) was applied at the beginning and ending and the data was tabulated. The graphics show that, in general, the 4 domains evaluated in the WHOQOL questionnaire had a better result (physical, psychological, social relations and environment) after chiropractic ajustments.
\end{abstract}

Keywords: volunteer, firefighters, Quality of Life, chiropractic, health 